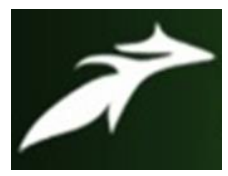

Chitrasena Padhy et al, International Journal of Advances in Agricultural Science and Technology,

Vol.7 Issue.11, November-2020, pg. 55-59

ISSN: 2348-1358

Impact Factor: 6.057

NAAS Rating: 3.77

\title{
Assessment of Mental Health and Psychological Counseling for Farmers
}

\author{
Chitrasena Padhy' ${ }^{1}$ Pakalpati Satyanarayana Raju² ${ }^{2}$ Kalee Prasanna Pattanayak ${ }^{3}$ \\ ${ }^{1}$ Ph.D Student/Assistant Professor, Department of Agricultural Extension, M S Swaminathan School of Agriculture, \\ Centurion University of Technology and Management, Odisha, India \\ ${ }^{2}$ Professor Emeritus, M.S. Swaminathan School of Agriculture, Centurion University of Technology and \\ Management, Odisha, India \\ ${ }^{3}$ Assistant Professor, School of Management, Centurion University of Technology and Management, Odisha, India \\ ${ }^{1}$ chitrasenapadhy@cutm.ac.in; ${ }^{2}$ profraju@ cutm.ac.in; ${ }^{3}$ kaleeprasanna@ cutm.ac.in
}

DOI: 10.47856/IJAAST.2020.v07i11.008

\begin{abstract}
Farmers at present are undergoing various kinds of stresses due to troubled situations such as high temperatures, heavy rains, periodic droughts, indebtedness, and low crop productivity. Isolation in farms affects them. They often show distress symptoms of clinical disorders like anxiety, depression, post traumatic stress, and suicidal tendency. Due to changing environment, they are facing increased levels of stress, worries, depression, problem in sleeping, emotional outbursts, dramatic changes in weight, substance abuse, and feelings of failure. Farmers can manage tough times by staying focused, connected, tuned to mass media channels for updated information, maintaining, and participation in social work. Farmers should keep sustained social contact, do plentiful of exercises, read an interesting book, participate in social activities, and involve in fun and frolic. In State Agricultural Universities (SAUs), psychology courses on mental health of farmers should be offered to agriculture students during graduation so that they can understand farmers' problems better and are trained to counsel farmers on proper psychological health care.
\end{abstract}

Keywords: Stresses, isolation, anxiety, emotional outbursts, mass media, social contact, social activities

\section{Introduction}

The Mountain Plains Mental Health Technology Transfer Center (MHTTC) addresses rural mental health and has recognized that accessibility, availability, and acceptability of mental health services by farming communities face great challenges. The center has developed resources and specific training to address mental health and suicidal tendencies among agricultural workers and their families (MHTTC, 2020). Michigan State University Extension's Farm Stress Program connects farmers experiencing stress and mental health issues with online counseling. The farmers can be linked with a licensed mental health therapist via telepathy by MSU Extension. The farmers can get mental health and counseling services through internet rather than in person. In traditional therapy face-to-face meetings are involved. In teletherapy, counseling session is conducted through video chat between mental health care providers and clients. By this advanced approach, people get the flexibility for accessing behavioural health supports in the comfort of their own environment. Farmers can get the needed behavioural health services even in the current COVID-19 "Stay Home, Stay Safe" executive order in Michigan (Karbowski et al., 2020). 


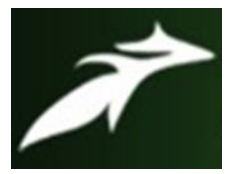

Chitrasena Padhy et al, International Journal of Advances in Agricultural Science and Technology,

Vol.7 Issue.11, November-2020, pg. 55-59

ISSN: 2348-1358

Impact Factor: 6.057

NAAS Rating: 3.77

\section{Stress Affects Farmers}

Due to COVID-19 pandemic, farmers are facing great difficulty dealing with uncertainty and confusion. They are not properly paid for their work, although they have to dump excess milk and plough under fields. In the context of such troubled situations, farmers may undergo depression and despair (Sorensen, 2020).

Climate change known as climate crisis is plaguing the environment increasingly. It has disastrous impact on people residing in cities or countries. However, people in rural areas are far more affected by climate change as they are in close proximity with nature and environment. Rural people are engaged with nature in agricultural occupations or agriculture related industries (Bommareddy, 2020).

There is effect of climate change on human health. Health hazards due to climate change happen to different people and different communities in varying degrees. Individually, exposure to multiple climate change threats happen, leading to health impacts. There are rising temperatures, heavy rains, and droughts. Some areas are experiencing health threatening climate and weather phenomena, for example severe heat or hurricanes and other worsening impacts like higher temperatures, more storm intensities, rainfall rates and storm surges. Areas not affected by toxic algal blooms or other water-borne diseases due to cooler water temperatures may face hazards in future. Climate change can affect in two ways, first it changes the severity of health problems of people previously unaffected by climate and creating surprising health problems in people in places where they did not occur previously. Due to climate change, the mental health consequences range from minimal stress and distress symptoms to clinical disorders like anxiety, depression, post traumatic stress, and suicidal tendency. There are other effects on perceptions and experiences of individuals and communities. Other social and environmental stressors have impact on mental health and well being (U.S.Global Change Research Programme, 2016).

High levels of stress and anxiety have effect on physical health. Chronic stress brings lowered immune system response. So people are more vulnerable to air and water pathogens and other physical ailments (Alderman et al., 2012; Simpson et al., 2011). One of the physiological responses of stress due to climate change is increased levels of the stress hormone cortisol, which in the long run can affect digestion, memory loss, and suppress the immune system (Doppelt, 2016).

Disasters bring a set of stressors that can hamper interpersonal interactions (Simpson et al., 2011). Natural disasters brought problems in family and interpersonal relationships, social disruption, concerns within wider community, and feelings of obligation to provide support to others (Norris et al., 2001). Families affected by flood, storm, or wild fire need to be relocated multiple times before settling permanently. Family relationships are affected. Separation from each other may happen. Children may not attend school or miss totally. Parents may not be able to be proper care takers. Those staying in their own homes may lose to sense their homes as safe and secure environments (Tapsell \& Tunstall, 2008).

Many things are uncertain in farming and outside farmers' control like market, trade, weather, and more. Due to the pandemic, farmers in Canada are facing depressed economy, market access, and trade disputes. The global pandemic added to the uncertainty and adversity. Farmers are generally resilient, but the pandemic can affect physically and mentally their families and employees. These lead to more stress, mental health challenges, and burnout (Kelley, 2020). 


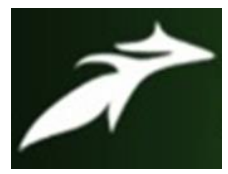

Chitrasena Padhy et al, International Journal of Advances in Agricultural Science and Technology,

Vol.7 Issue.11, November-2020, pg. 55-59

ISSN: 2348-1358

Impact Factor: 6.057

NAAS Rating: 3.77

\section{Mental Healthcare Strategies}

University of Exter has been appointed by the farming charity RABI to conduct a "once-in-a-generation survey of farming people" for helping understand mental and physical wellbeing issues in agriculture. The research project is said to be the largest survey to gain an understanding directly from farming people who are facing stresses and how these challenges are affecting their wellbeing (Barker, 2020).

A mental health app has been developed by Innovation Saskatchewan in partnership with the Agriculture Ministry to help farmers deal with personal stresses they may face. The farmers can use this app in privacy of their own home and ask for help, said Tina Beaudry-Mellor, the minister responsible for Innovation Saskatchewan (Simes, 2020).

As the environment is changing, farmers are experiencing increased stress levels. Early signs of farmers' troubles are feeling worried, depressed, problem in sleeping, emotional outbursts, dramatic changes in weight, substance abuse, feelings of failure, and isolation. Farmers should note that they are not alone. Resources are available for those who are in need (AgCountry Farm Credit Services, 2020).

Tips for Managing Farm Stress Through Uncertain Times (Kelley, 2020)

(1) Stay focused: Stay focused on what you can control. When things go out of control, the farmers can focus on what they can control. That can keep them feel empowered. One may not be able to know who contracts COVID-19, but can control things like hand washing, disinfecting machinery, and where people come in contact in shop areas. One can keep up to date records, self care activities, and communicating with the team and family.

(2) Stay connected: Stay connected with your family and friends in this time through phone calls or social distancing. One can express feelings with a spouse, a family member, and a friend.

(3) Tune out: Nowadays 24 hour news is available everyday can be valuable for the farmers to get important information. Taking a media break is also important if it is negatively impacting their mental health.

(4) Maintain health: To maintain one's health, one should eat at right time, get fresh air, and drink enough water for maintaining good physical health. It will have positive impact on the mental health.

(5) Do some good: Helping others, utilizing time and energy by volunteering, can help feel good as well. It helps to get over the hard times.

(6) Embrace the good: People learn to be resilient by going through adversity. In hard times, one should do positive things and embrace the opportunity to see, grow and learn from.

(7) Do not forget to play: One shoud spend time with something that makes one feel good, like moving outside, playing with the family or trying a new recipe.

(8) Know it is okay to feel many different things: Anxiety, worry, uncertainty, and fear are all normal feelings to have and one should take help if these feelings can disrupt daily life.

Researchers have found a programme that aims to improve mental health of farmers. The programme is named 'In the Know". In this four-hour course producers can join to understand better the mental health and for confidence building. The researchers from University of Guelph have developed this and shared in the annual Canadian Agricultural Safety Association Conference in Quebec City ( Simes, 2019).

Punjab Agricultural University, Ludhiana, conducted a survey on addressing farmers' distress through capacity building of farming families. It requested to include farmers' suicide prevention plan in the national suicide prevention plan. It suggested universal screening of vulnerable farmers and strong mental healthcare required for 


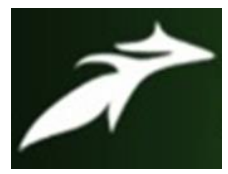

Chitrasena Padhy et al, International Journal of Advances in Agricultural Science and Technology,

Vol.7 Issue.11, November-2020, pg. 55-59

ISSN: 2348-1358

Impact Factor: 6.057

NAAS Rating: $\mathbf{3 . 7 7}$

them. In the report it suggested for change in course studies in State Agricultrural Univeresities (SAUs) for introducing psychology and mental healthcare of farmers in the extension services and kisan kendras. The report was submitted to the Indian Council of Agricultural Research, New Delhi, and it was based on findings from 16 worst affected districts of Punjab, Maharashtra, and Telengana (Kant, 2020).

\section{Conclusion}

Young Farmers' Clubs play an important role in emphasizing the importance of mental health as much as their physical health. During the Mental Health Awareness Week, 2020, the initiative was launched by the National Federation of Young Farmers' Clubs (NFYFC). This initiative came as the United Nations warned of a global mental health crisis due to the impact of the corona virus pandemic. Isolation is a major issue for young people. The members were not able to meet their friends from March 2020 due to the restrictions imposed during Covid-19. The online 'Take Time Toolkit' may solve some of these problems faced by the young people (Farming UK Team, 2020).

Farmers should be trained on how to take proper psychological healthcare during stressful periods. After getting training, they should suggest the methods of coping stress to other fellow farmers.

\section{References}

[1]. AgCountry Farm Credit Services, 2020, Mental Health Resources for Farmers, https://www.agcountry.com/Tools/mental-health-resources-for-farmers.

[2]. Alderman, K., Turner, L. R., \& Tong, S. 2012. Floods and human health: A systematic review. Environment International, 47, 37-47. doi:10.1016/j.evint.2012.06.003.

[3]. Bommareddy Pooja, 2020, The Burning Mental Health of Farmers, https://letmebreathe.in/2020/08/21/theburning-mental-health-of-farmers/.

[4]. Doppelt, B. 2016. Transformational resilience: How building human resilience to climate disruption can safeguard society and increase wellbeing. Sheffield, England: Greenleaf.

[5]. Farm Stress and Mental Health, MHTTC,2020, https://mhttcnetwork.org/centers/mountain-plainsmhttc/home.

[6]. Farming UK Team, 2020, Corona virus: Young farmers urged to look after mental health, https://www.farminguk.com/news/coronavirus-young-farmers-urged-to-look-after-mentalhealth_55673.html.

[7]. Jeremy Simes, 2019, Mental health course for farmers aims to go nationwide. https://www.producer.com/2019/11/mental-health-course-for-farmers-aims-to-go-nationwide/.

[8]. Kant Aditya, 2020, Farmers must be screened, get access to robust mental health care: Study, https://imesofindia.indiatimes.com/city/chandigarh/farmers-must-be-screened-get-access-to-robust-mentalhealth-care-study/articleshow/74291626.cms.

[9]. Karbowski Eric, Gross Paul, 2020, MSU Extension Farm Stress Program partners to connect farmers with mental health services, https://www.canr.msu.edu/news/msu-extension-farm-stress-program-partners-toconnect-farmers-with-mental-healthservices\#: :text=Michigan\%20State\%20University\%20Extension's,mental\%20health\%20therapist\%20via $\% 20$ teletherapy.

[10]. Kelley Lesley, 2020, The Do More Agriculture Foundation, Managing Stress on the Farm During Covid19, https://www.domore.ag/blog/managing-stress-on-the-farm-during-covid-19. 


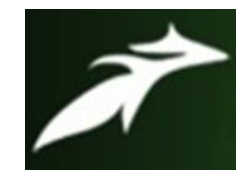

Chitrasena Padhy et al, International Journal of Advances in Agricultural Science and Technology,

Vol.7 Issue.11, November-2020, pg. 55-59

ISSN: 2348-1358

Impact Factor: 6.057

NAAS Rating: 3.77

[11]. Michael barker, 2020, Biggest-ever survey into farmer mental health. http://www.fruitnet.com/fpj/article/183391/biggest-ever-survey-into-farmer-mental-health.

[12].Norris, F., Byrne, C., Diaz, E., \& Kaniasty, K. 2001. The range, magnitude, and duration of effects of natural and human-caused disasters: A review of the empirical literature. White River Junction, VT: National Centre for Post-Traumatic Stress Disorder, Department of Veterans Affairs.

[13].Simpson, D. M., Weissbecker, I., \& Sephton, S. E. 2011. Extreme weather-related events: Implications for mental health and well-being. In I. Weissbecker (Ed.), Climate change and human well-being: Global challenges and opportunities (pp. 57-78). New York, NY: Springer.

[14].Sorensen Jason, 2020, Mental health risk: Farmers offered support, help. https://www.fairmontsentinel.com/news/local-news/2020/05/11/mental-health-risk-farmers-offeredsupport-help/.

[15].Tapsell, S. M., \& Tunstall, S. M. 2008. "I wish I'd never heard of Banbury": The relationship between "place" and the health impacts of flooding". Health \& Place, 14(2), 133-154.

[16].U.S. Global Change Research Program. 2016. The impacts of Climate Change on Human Health in the United States: A Scientific Assessment. https://health2016.globalchange.gov/. 